\title{
A COMBINED AHP-DELPHI APPROACH TO ASSESS THE SOCIAL RESPONSIBILITY DEGREE OF EQUITY MUTUAL FUNDS
}

\author{
Mónica García-Melón \\ INGENIO (CSIC-UPV) \\ Universitat Politècnica de València \\ Camino de Vera s/n, \\ 46022 Valencia, Spain. \\ E-mail: mgarciam@dpi.upv.es \\ Tomás Gómez-Navarro \\ Engineering Projects Department \\ Universitat Politècnica de València \\ Camino de Vera $\mathrm{s} / \mathrm{n}$, \\ 46022 Valencia, Spain. \\ E-mail: tgomez@dpi.upv.es \\ Blanca Pérez-Gladish \\ Quantitative Economics Department \\ University of Oviedo \\ Avda. Del Cristo s/n, \\ 33006 Asturias, Spain \\ E-mail: bperez@uniovi.es \\ Paz Mendez-Rodriguez \\ Quantitative Economics Department \\ University of Oviedo \\ Avda. Del Cristo s/n, \\ 33006 Asturias, Spain \\ E-mail: bperez@uniovi.es
}

\begin{abstract}
The aim of this paper is to propose a ranking method for Spanish equity mutual funds based on multiple social responsibility criteria, which could allow individual and institutional investors to make investment decisions based on a set of agreed social responsible values. In order to reach this goal three key questions have been addressed: the identification of the main stakeholders; the definition of an agreed list of socially responsible investment criteria and, the determining of the agreed relative importance given to each criterion in the decision making process. In order to calculate this relative importance of the criteria a participative AHP procedure has been carried out.
\end{abstract}

Keywords: CSR, equity funds, stakeholders involvement, AHP. 


\section{Introduction}

Socially responsible investing (SRI), frequently called ethical investment or sustainable investment, is broadly defined as an investment process that integrates social, environmental, governance and ethical considerations into investment decision-making. Socially responsible mutual funds (SRMF) are one of the main instruments of SRI. The term 'fund' is used to refer to a ready-made financial product where investors' money is pooled into a portfolio and a fund manager decides which shares to buy. A socially responsible fund is a fund where the selection of investments is based not only on financial but also on social, environmental, governance or other ethical criteria.

Those non-financial criteria are diverse and diverge in a large degree from one fund to another. On the other hand, the information provided by the mutual funds with regard to the applied selection criteria is not always clear enough for passive investors who rely on the fund manager's judgment to select investments.

Because investors have a limited capacity for handling extensive information, there is a growing demand for instruments tailored to the investors' needs. The social responsibility rating of a fund can provide the desired transparency and should complement the existing financial rating. Interestingly enough, to date the non-financial rating for mutual funds is less developed than the financial counterpart. As far as the authors of this paper know, although numerous works have been published exploring Corporate Social Performance (CSP) measures and rating, very few academic studies can be found in the literature concerning mutual funds' socially responsibility performance measurement and nonfinancial rating.

Although socially responsible preferences can differ from one investor to another depending on cultural and personal values and so, the decision making criteria and their weights, the availability of a ranking for mutual funds based on a set of common nonfinancial criteria agreed by the main stakeholders could be helpful for those investors without a clearly pre-defined socially responsible investment profile.

The aim of this paper is to propose a ranking method for Spanish equity mutual funds based on multiple social responsibility criteria, which could allow individual and institutional investors to make investment decisions based on a set of agreed social responsible values. In order to reach this goal three key questions have been addressed: the identification of the main stakeholders; the definition of an agreed list of socially responsible investment criteria and, the determining of the agreed relative importance given to each criterion in the decision making process.

\section{Literature Review}

In his categorization of the responsible investment literature Hoepner (2007) identifies 14 papers dealing with the definition of criteria for social, environmental and ethical screening in responsible investment. In practice, several independent agencies try to supply transparent and credible information about the social, labor and environmental performance of companies throughout the world. Some examples are KLD, Ethibel, Vigeo, Innovest, Oekom Research, SAM, Jantzi Research, Corporate Monitoring, EthicScan Canada, EIRIS, etc. But few rating agencies monitor mutual funds for social responsibility criteria. Most of the agencies provide financial information about the funds (costs, performance, risk and liquidity) and conventional investment strategy information (type of security, country and industry allocation, financial investment objectives and 
fund composition). They also include some information related to the ethical investment strategy and about portfolio building but the level of transparency and extension of the explanations differ from one agency to another.(Gomez-Navarro, 2013)

In this work we will rely on Vigeo's list of social, environmental, governance and ethical criteria as a departure point for the discussion and obtaining of an agreed list of nonfinancial criteria for socially responsible ranking of mutual funds. Vigeo is a leading European expert in the assessment of companies and organisations with regard to their practices and performance on Environmental, Social and Governance (ESG) issues. Vigeo has developed Equitics ${ }^{\circledR}$ a model based on internationally recognised standards with which they assess the degree to which companies under review take the social responsibility objectives of their analysis ratings model into account in the definition and deployment of their strategy. They offer access to ratings in the 6 domains: Human Rights; Human Resources; Environment; Business Behaviour; Corporate Governance and Community Involvement. They consider 44 non-financial criteria and provide more than 300 indicators for each company.

As main stakeholders we have decided to consider the five groups identified by SpainSif (Spanish Social Investment Forum). (Perez-Gladish, 2013) The identification of main stakeholders for the discussed problem in this paper is a new contribution as usually they are identified in the context of the firms and their Corporate Social Responsibility (CSR). In this paper stakeholders are those groups with interest on the existence of a ranking for mutual funds based on social responsibility criteria.

Once the main stakeholders, the agreed criteria and, the preferential weights have been obtained we will evaluate and rank equity mutual funds. We will rely on two different databases: Vigeo's firms CSR rating and Morningstar Inc. We will adapt Vigeo's rating based on their Equitics criteria to our agreed list of criteria and then, given the weights of each firm in each mutual fund which are provided by Morningstar we will evaluated and rank equity mutual funds..

\section{Research Design/Methodology}

Based on all previously mentioned, to assess the social value of the Spanish mutual funds we propose the following methodology: 
IJAHP Article: Mu, Saaty/A Style Guide for Paper Proposals To Be Submitted to the International Symposium of the Analytic Hierarchy Process 2014, Washington D.C., U.S.A.

\section{Data/Model Analysis}

The AHP model used was the following:

\section{Foreseen discussion of results and conclusions}

This paper will present the results of an ongoing research that is not yet complete. However, some first results can be foreseen and some conclusions can be drawn that show the interest of the investigation.

Firstly, this research fulfills its aim of starting and helping to guide a discussion on how to assess and rank order the social responsibility (SR) of companies and equity funds. The obtained results must not be taken as a concluding rank order of companies or funds. They are more intended to show the feasibility of the discussion than to actually judge the SR of a particular company or fund.

Therefore, the results allow the authors of this paper to argue the companies' social responsibility (SR), and the funds' SR they participate in, can be and should be measured. The difficulties tackled are discussed and recommendations to overcome them are put forward. AHP has proven to be a suitable and reliable method to assess the SR, to help discussing different approaches and preferences, to help reaching as much consensus as possible and to communicate the criteria importance to the stakeholders. 
However, the research has shown companies' SR data are not entirely consistent in detail, time or reliability. For the procedure some estimations had to be done to fill in the gaps. Therefore, among the results, some recommendations for better SR screening are put forward.

AHP allows analyzing the aggregate results or to study them by separate. The preferences of each stakeholder can be compared, the individual importance of each criteria can be highlighted, etc. Furthermore, a sensitivity analysis can be carried out to determine the rigor and accuracy of the results and their dependence with each single variable.

Moreover, the criteria weights, and hence the companies' and funds' rankings, can be edited according to each stakeholder's preference. This way, on the one hand, a particular investor can choose the best ranked equity fund consistent with his preferences. On the other hand, an equity fund designer or manager can adapt the fund's composition in order to achieve the investors' demands.

The involved stakeholders are appreciating these advantages and they are following the procedure proving its feasibility. However, the amount of judgments and the complexity of some comparisons are mentioned as the weaknesses of the method. Hence, some abridged procedures are being designed to spread out the participation in the assessments.

The procedure has attracted the interest of the institutional and individual investors that, for different reasons, are interested in assessing the social performance of the equity funds beyond their profitability.

\section{Key References}

Gómez-Navarro Tomás, Baviera-Puig Amparo, García-Martínez, Gabriel, (2013), Assessing the Corporate Social Responsibility Reports Based on Communication Indicators: An ANP Aproach, XII International Symposium on the Analytic Hierarchy Process. Kuala Lumpur. Malasia.

Hoepner, A., (2007), A categorization of the responsible investment literature, St. Andrews Sustainability Institute Research Papers, june 2007

Perez-Gladish, B. (2012) Profiling Socially Responsible Investors: Australian Evidence, Australian Journal of Management, 37

Saaty, T. (1996), The analytic hierarchy process. Planning. Priority Setting. Resource Allocation, Pittsburgh: RWS Publications 